\title{
ESTUDO EPIDEMIOLÓGICO DE LESÕES BUCAIS NO AMBULATÓRIO DE ESTOMATOLOGIA DO HOSPITAL GERAL DE CURITIBA
}

Fábio Alves IZIDORO, Ana Claudia Santos de Azevedo IZIDORO, Andressa Marafon SEMPREBOM, Roberta Targa STRAMANDINOLI, Lucia Fatima de Castro ÁVILA

Os autores apresentam o primeiro levantamento estatístico (biênio 2005/2007) do Ambulatório de Estomatologia do Hospital Geral de Curitiba ( $\mathrm{HGeC}$ ). Além do atendimento ambulatorial, a equipe examina pacientes no leito, e participa de campanhas de prevenção do Câncer Bucal durante as Ações Cívico-Sociais do Exército Brasileiro. Nesse período foram atendidos 60 pacientes, com média de idade de 51 anos, 42 do sexo feminino e 18 do sexo masculino. Realizaram 39 biópsias. A partir da análise dos prontuários e dos laudos dos exames histopatológicos, avaliou-se a prevalência das lesões bucais de tecidos moles. As alterações observadas foram classificadas como: 1)processos proliferativos não neoplásicos - $26,6 \%(16 / 60)$, 2) lesões pigmentadas (negras) - 6,6\% (4/60), 3)doenças infecciosas (estomatite protética) - 10,0\% (6/60); 4)tumores benignos (tecido mole) - 6,6\% (4/60), 5) glândulas salivares (mucocele) - 8,3\% (5/60), 6)lesões e condições cancerizáveis - 25,0\% (15/60) e 7) outras - 16,6\% (10/60). Os resultados demonstraram um predomínio das lesões proliferativas não neoplásicas e também lesões e condições cancerizáveis. Lesões raras como cisto linfoepitelial bucal e fibromatose gengival hereditária também foram diagnosticadas. Concluem que maiores cuidados no diagnóstico preciso das lesões bucais são necessários, considerando-se o alto número de lesões proliferativas relacionadas freqüentemente a iatrogenias, além da importância do diagnóstico precoce do câncer bucal. 